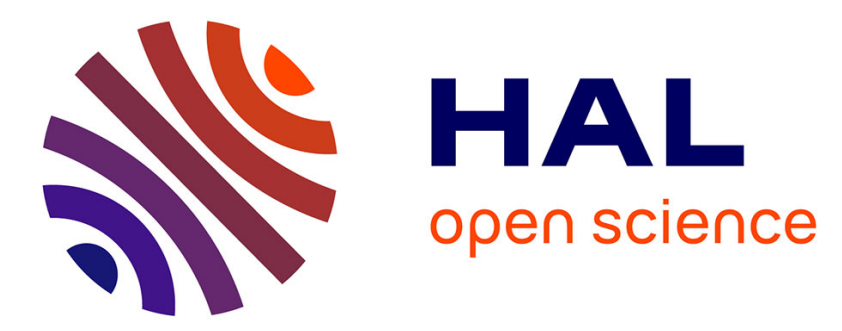

\title{
Sliding Mode Observer Design for Battery State of Charge estimation
}

\author{
H Bouchareb, K Saqli, Nacer K M'Sirdi, Mohammed Oudghiri, A. Naamane
}

\section{To cite this version:}

H Bouchareb, K Saqli, Nacer K M'Sirdi, Mohammed Oudghiri, A. Naamane. Sliding Mode Observer Design for Battery State of Charge estimation. REDEC'20 the International Conference on Renewable Energy for Developing Countries, Mar 2020, Marrakech, Morocco. hal-02486436

\section{HAL Id: hal-02486436 https://hal.science/hal-02486436}

Submitted on 21 Feb 2020

HAL is a multi-disciplinary open access archive for the deposit and dissemination of scientific research documents, whether they are published or not. The documents may come from teaching and research institutions in France or abroad, or from public or private research centers.
L'archive ouverte pluridisciplinaire HAL, est destinée au dépôt et à la diffusion de documents scientifiques de niveau recherche, publiés ou non, émanant des établissements d'enseignement et de recherche français ou étrangers, des laboratoires publics ou privés. 


\section{Sliding Mode Observer Design for Battery State of Charge estimation}

\author{
H. Bouchareb \\ University of Sidi Mohamed Ben Abdellah \\ National School of Applied Sciences \\ Fez, Morocco \\ houda.bouchareb.seii@gmail.com \\ N.K. M'sirdi \\ Aix Marseille University \\ LIS Laboratory of Informatics and Systems \\ Marseille, France \\ msirdink@gmail.com
}

\author{
K. Saqli \\ University of Sidi Mohamed Ben Abdellah \\ National School of Applied Sciences \\ Fez, Morocco \\ saqli.khadijah@gmail.com \\ M. Oudghiri Bentaie \\ University of Sidi Mohamed Ben Abdellah \\ National School of Applied Sciences \\ Fez, Morocco \\ oudghiri.ensafes@gmail.com \\ A. Naamane \\ Aix Marseille University \\ LIS Laboratory of Informatics and Systems \\ Marseille, France \\ aziz.naamane@lis-lab.fr
}

\begin{abstract}
To ensure safe, reliable and efficient operations of the traction batteries under the most demanding and grueling driving conditions, an effective Battery Management System (BMS) must be used. However, an efficient battery model and and accurate prediction of the battery internal states are required.

In this paper, lithium-ion battery is modeled as a second-order RC Equivalent Circuit Model. Furthermore, the battery State of Charge is then estimated based on an improved sliding mode observer.

Index Terms-Battery Management System, Sliding Mode Observer Design,Lithium-ion Battery, Equivalent Circuit Model, State of Charge Estimation.
\end{abstract}

\section{INTRODUCTION}

Electric vehicles (EVs) represent interesting opportunities as a technology to reduce greenhouse gas emissions in the transport sector, one of the largest emitting sectors. They are also considered to be a tool for reducing local air pollution. According to Business, Energy and Industrial Strategy Committee in UK, International market trends suggest that electric cars and vans will reach price equivalency with internal combustion engine (ICE) vehicles by the mid-2020s, and that EV sales will overtake petrol and diesel sales by the late 2030s [1]. EV batteries denote the main determinant of both the range and cost of the vehicle, thought to be the major limitations on their sales. Therefore, a careful choice of the battery chemistry is what differentiates the automotive market products.

Thanks to their high energy density, high power density and long cycle life, Lithium-ion batteries have become the main storage component of EVs. Due to the fact that Lithiumion batteries may present an operating failure if overcharged, completely discharged or operated outside their safe temperature window, they all require a Battery Management System (BMS).

Among the key features of the BMS is the estimation of the battery internal states and especially its state of charge SOC. SOC is defined as a ratio of the remaining capacity to the nominal capacity of the cell. Knowledge of the state of charge conditions the driver's confidence in his vehicle. Its value gives the driver an idea of the remaining period of safe use. However, since the internal states of battery cells can not be directly measured using sensors, advanced mathematical algorithms are required to estimate the SOC.

A variety of SOC estimation techniques have been reviewed in literature, in order to estimate state of charge precisely and accurately. In reference [2], the estimation methods were classified into four main categories:

- The direct measurement methods estimate the SOC based on the battery's physical properties. For example, the Open Circuit Voltage method uses the stable battery electromotive force in the open circuit state and SOC relationship to estimate the SOC value [3].

- Book keeping estimation methods use the battery charge and discharge current as an input. Among the methods belonging to this category, we find the coulomb counting method which integrates the battery charging / discharging current over time to find SOC [4].

- In model-based methods, the battery parameters and SOC are estimated using adaptive filters and observers [5]-[8].

- The last methods require high computational time and 
storage size and are based purely on computer intelligence [9]-[11].

In this paper, a second-order RC Equivalent Circuit Model (ECM) is realized and their parameters are then identified, based on an electrochemical-thermal battery pack of three parallel connected cylindrical Lithium-ion cells modelled in our previous work using COMSOL Multiphysics. The Sliding Mode Observer method is then investigated and studied for battery SOC estimation. Moreover, an improved version of this technique is presented and applied in order to estimate more accurately the battery SOC.

\section{BATTERY MODEL}

Building an accurate battery model represents an essential task in BMS design to improve the battery internal states estimation accuracy. According to literature, battery modeling methodologies can be classified into two main categories: Electrochemical Models (EMs) and Equivalent Circuit Models (ECMs) [12].

Electrochemical models give a detailed description of physical and chemical processes occurring inside the battery cell using coupled Partial Differential Equations (PDEs) [13], [14]. However, EMs suffer from a major drawback being the complexity of solving the partial differential equations specially for real time applications. Equivalent Circuit Battery (ECM) models have been presented as an alternative of EMs in order to simplify their computational complexity. According to literature, ECMs include the Rint model, the Partnership for a New Generation of Vehicle (PNGV) model, the Thevenin model and the second-order resistor-capacitor (2RC) model [15]. These models use electrical components as voltage sources, resistors and capacitors to model the dynamic behavior of the battery. In this paper, the second-order RC model is chosen to model the Lithium-ion battery since it balances the accuracy and availability in online applications [16]. It consists of an ideal voltage source Uoc, an ohmic resistance R0, and two RC parallel circuits, as shown in Fig.1.

The circuit components are chosen so that each represents a specific aspect of the battery. The internal resistance R0 is responsible for the immediate voltage rise or drop when the battery is being charged or discharged. The RC parallel polarization blocks are responsible for the transient response of the battery.

According to the second-order RC equivalent circuit model (figure 1), the battery terminal voltage is expressed by applying the Kirchhoff's theorem to this electrical circuit:

$$
U_{b}(t)=U_{O C}(S O C)-R_{0} \times I(t)-U_{R C 1}(t)-U_{R C 2}(t)
$$

where $U_{O C}$ denotes the Open Circuit Voltage (OCV) of the battery. The author has chosen to adopt a sixth-order polynomial equation describing the nonlinear relationship between the OCV and the SOC, as presented in [20]:

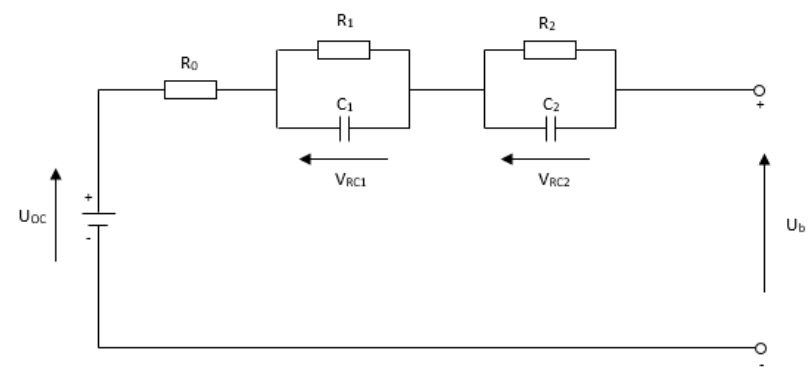

Fig. 1. Schematic diagram of the second-order equivalent circuit model

$$
\begin{gathered}
U_{O C}(S O C)=14.7958 \times S O C^{6}-36.6148 \times S O C^{5} \\
+29.2355 \times S O C^{4}-6.2817 \times S O C^{3}-1.6476 \times S O C^{2} \\
+1.2866 \times S O C+3.4049
\end{gathered}
$$

Based on the coulomb counting method, the SOC is expressed as:

$$
S \dot{O} C(t)=\frac{-\eta}{Q} \times I(t)
$$

where $\eta$ is the battery coulombic efficiency and $Q$ is the rated capacity of the battery. The voltage dynamics of the two $\mathrm{RC}$ networks can be then given as follows:

$$
\begin{aligned}
& \dot{U}_{R C_{1}}(t)=\frac{-1}{R_{1} \times C_{1}} \times U_{R C_{1}}(t)+\frac{1}{C_{1}} \times I(t) \\
& \dot{U}_{R C_{2}}(t)=\frac{-1}{R_{2} \times C_{2}} \times U_{R C_{2}}(t)+\frac{1}{C_{2}} \times I(t)
\end{aligned}
$$

As a result, the electrical behaviour of the proposed model can be summarized as follows:

$$
\begin{gathered}
{\left[\begin{array}{l}
S \dot{O} C \\
\dot{U_{R}}(t) \\
\dot{U_{R}}(t) \\
U_{R C_{2}}(t)
\end{array}\right]=\left[\begin{array}{c}
\frac{-\eta}{Q} \times I(t) \\
\frac{-1}{R_{1} \times C_{1}} \times U_{R C_{1}}(t)+\frac{1}{C_{1}} \times I(t) \\
\frac{-1}{R_{2} \times C_{2}} \times U_{R C_{2}}(t)+\frac{1}{C_{2}} \times I(t)
\end{array}\right]} \\
{\left[U_{b}(t)=U_{O C}-R_{0} \times I(t)-U_{R C_{1}}-U_{R C_{2}}\right]}
\end{gathered}
$$

\section{BATTERY PARAMETERS EstimATION}

The model parameters are estimated by discharging the electrochemical-thermal battery model developed in our previous work [32], using a multipulse discharge current of 30 s, each followed by a relaxation period of 120 s at various temperatures. The parameter estimation process is performed for each temperature in order to identify the values of the various battery parameters during its discharge, as shown in the graphs below [17]. 

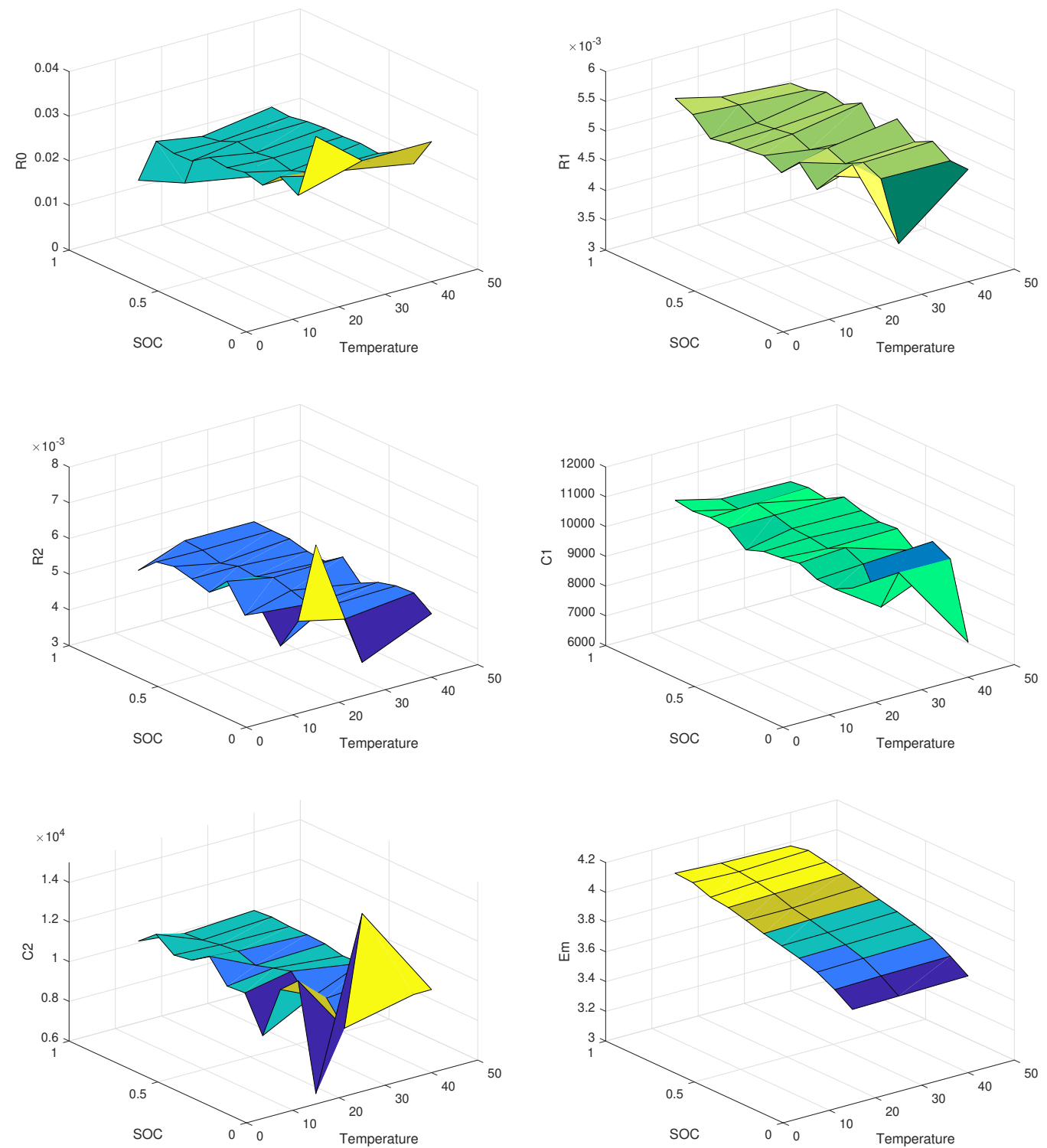

Fig. 2. Battery model parameters

\section{BATtery State of Charge Estimation}

\section{A. Sliding Mode Observer Design}

In accordance with the established second-order equivalent circuit model and parameter identification of lithium-ion battery, aiming to improve the estimation accuracy of lithium battery SOC, an improved sliding mode observer for SOC estimation of lithium battery is proposed in this section.

A sliding mode observer is developed as to think of the observer system as comprising a model of the plant together with a feedback term which corrects the estimates by injecting back the discrepancy between its output and the output of the system, through a designer-specified gain. In this observer form, instead of feeding back the output error between the observer and the system in a linear fashion, the output error is fed back via a discontinuous switched signal [18], [19].

Based on equations 8 and 9, the state-space model used to estimate the SOC can be derived as follows:

$$
\dot{x}=A x+B u
$$

$$
y=h(x)+D u
$$

where the system state matrix $\mathrm{A}$, the system input matrix 
$\mathrm{B}$ and the coupling matrix $\mathrm{D}$ are defined as:

$$
\begin{gathered}
A=\left[\begin{array}{ccc}
0 & 0 & 0 \\
0 & -a_{1} & 0 \\
0 & 0 & -a_{2}
\end{array}\right] ; a_{1}=\frac{1}{R_{1} \times C_{1}} ; a_{2}=\frac{1}{R_{2} \times C_{2}} \\
B=\left[\begin{array}{ccc}
\frac{-1}{Q} & \frac{-1}{C_{1}} & \frac{-1}{C_{2}}
\end{array}\right]^{T} \\
h(x)=U_{O C}(S O C(t))-U_{R C_{1}}-U_{R C_{2}} \\
D=\left[R_{0}\right]
\end{gathered}
$$

The system state vector $\mathrm{x}$, the input vector $\mathrm{u}$ and the output vector $y$ are chosen as follows:

$$
\begin{aligned}
& x=\left[\begin{array}{lll}
S O C(t) & U_{R C_{1}}(t) & U_{R C_{2}}(t)
\end{array}\right]^{T} \\
& u=[I(t)] \\
& y=\left[U_{b}(t)\right]
\end{aligned}
$$

According to the system state representation (8) and (9), the SMO based estimation can be written as:

$$
\begin{aligned}
& \dot{\hat{x}}=A \hat{x}+B u+L(y-\hat{y})+M(e, \rho) \\
& =A \hat{x}+B u+K e_{y} \\
& \hat{y}=h(\hat{x})+D u \\
& M(e, \rho)= \begin{cases}s(\|e\|, \rho) & e \neq 0 \\
0 & e=0\end{cases}
\end{aligned}
$$

where $K$ denotes the feedback gain matrix, $\hat{x}$ denotes the observation value of $\mathrm{x}$, and $\dot{h}(x)$ denotes the derivative of $h(x)$.

The observability of the battery SOC estimation system is proven by demonstrating that the observable matrix is full rank [3]. The observable matrix of nonlinear system is defined as the Jacobian of the vector $\mathrm{o}(\mathrm{x})$ :

$$
O=\frac{d o(x)}{d x}=\frac{d}{d x}\left(\left[\begin{array}{c}
h(x) \\
L_{f} h(x)
\end{array}\right]\right)
$$

where $x$ is system state matrix and $L_{f}$ is the Lie derivative of function, which is defined as:

$$
L_{f} h(x)=\frac{d h(x)}{d x} \times \dot{x}
$$

Applying this to the battery state model proposed in this paper, $h(x)$ and $L_{f}$ are presented as follows:

$$
\begin{gathered}
h(x)=U_{O C}-U_{R C_{1}}-U_{R C_{2}} \\
L_{f} h(x)=\frac{1}{R_{1} C_{1}} \times U_{R C_{1}}
\end{gathered}
$$

Then, substituting equations (21) and (22) into equation (19), the observable matrix of the battery system is:

$$
O=\left[\begin{array}{cc}
1 & \frac{d}{d t}\left(U_{O C}\right) \\
\frac{1}{R_{1} C_{1}} & 0
\end{array}\right]
$$

Since $\frac{d}{d t}\left(U_{O C}\right) \neq 0$ based on equation (2), $\mathrm{O}$ is then a full rank matrix. Therefore, the system is observable.

The SMO based on the battery model and used to estimate accurately the battery SOC is proposed as follows [21], [22]:

$$
\left[\begin{array}{c}
\dot{\hat{x_{1}}} \\
\dot{\hat{x_{2}}} \\
\dot{\hat{x_{3}}}
\end{array}\right]=\left[\begin{array}{c}
\frac{1}{Q} u-l_{3} e_{y}-c_{1} \\
-a_{1} \hat{x_{1}}-\frac{1}{C_{1}} u-l_{2} e_{y}-c_{2} \operatorname{sqn}\left(e_{y}\right) \\
-a_{2} \hat{x_{2}}-\frac{1}{C_{2}} u-l_{3} e_{y}-c_{3} \operatorname{sqn}\left(e_{y}\right)
\end{array}\right]
$$

And,

$$
\left[\begin{array}{c}
\dot{\hat{x_{1}}} \\
\dot{\hat{\hat{R}_{2}}} \\
\dot{\hat{x_{3}}}
\end{array}\right]=\left[\begin{array}{c}
\frac{1}{Q} u-k_{3} e_{y} \\
-a_{1} \hat{x_{1}}-\frac{1}{C_{1}} u-k_{2} e_{y} \\
-a_{2} \hat{x_{2}}-\frac{1}{C_{2}} u-k_{3} e_{y}
\end{array}\right]
$$

where $e_{y}=y-\hat{y}, \operatorname{sgn}$ is the approximate expression of signum function and is defined as:

$$
\operatorname{sgn}\left(e_{y}\right)=\frac{e_{y}}{0.05+\left|e_{y}\right|}
$$

The constants $k_{i}(i=1,2,3)$ is defined as follows:

$$
l_{i}<k_{i}=l_{i}+\frac{c_{i}}{\left|e_{y}\right|+0.05}<l_{i}+\frac{c_{i}}{0.05}
$$

\section{B. Results and Discussion}

For the sake of confirming the applicability of the proposed SMO method used to estimate the battery SOC and verify its results accuracy, the proposed battery was investigated in a real-time EV application, by applying as system input the current generated by Urban Dynamometer Driving Schedule (UDDS) tests, presented as follows:

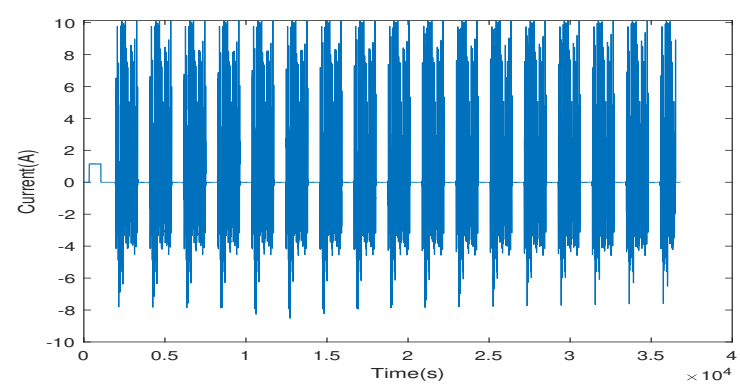

Fig. 3. Input current profile - UDDS Test

In this section, a simulation experiment is built based on the SOC estimation second-order RC ECM model, in order to confirm the effectiveness and accuracy of the proposed improved SMO algorithm.

The following figure presents a comparison between real SOC values and SOC values obtained using the proposed SMO algorithm: 


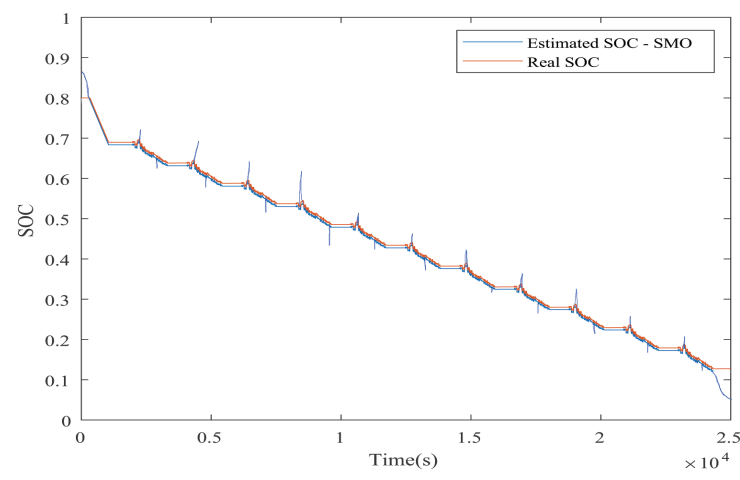

Fig. 4. SOC estimation curve

\section{Conslusion}

This research paper proposed an enhanced SMO to estimate SOC of lithium-ion batteries. An equivalent circuit model with $2 \mathrm{RC}$ networks is built up. This model parameters were then identified on the basis of measurement data required from a 3D electrochemical-thermal battery pack developed previously in COMSOL Multiphysics. Then, an enhanced SMO was designed and used to estimate SOC of the Li-ion battery.

Simulation results denote that the proposed SMO algorithm presents high accuracy by improving the robustness of SOC estimation. The proposed model can be further improved to take into account both hysteresis and battery aging factors as residual capacity, internal resistance and peak power. And to predict other battery states.

\section{REFERENCES}

[1] House of Commons. Business, Energy and Industrial Strategy Committee, "Electric vehicles : driving the transition.", Fourteenth Report of Session 2017-19.

[2] Muhammad Umair Ali, Amad Zafar, Sarvar Hussain Nengroo, Sadam Hussain, Muhammad Junaid Alvi and Hee-Je Kim, ”Towards a smarter battery management system for electric vehicle applications: A critical review of Lithium-Ion battery state of charge estimation". The Journal of Energies 2019, vol. 12, pp. 446; doi: https://doi.org/10.3390/en12030446.

[3] Muhammad Umair Ali, Amad Zafar, Sarvar Hussain Nengroo, Sadam Hussain, Muhammad Junaid Alvi and Hee-Je Kim, ”Towards a smarter battery management system for electric vehicle applications: A critical review of Lithium-Ion battery state of charge estimation". The Journal of Energies 2019, vol. 12, pp. 446; doi: https://doi.org/10.3390/en12030446.

[4] Xie Jiale, Ma Jiachen and Bai Kun, ”Enhanced coulomb counting method for state-of-charge estimation of lithium-ion batteries based on peukert's law and coulombic efficiency". Journal of Power Electronics 2018, vol. 18 issue 3, pp. 910-922; doi: https://doi.org/10.6113/JPE.2018.18.3.910.

[5] Qiao Zhu, Neng Xiong, Ming-Liang Yang, Rui-Sen Huang and GuangDi Hu, State of Charge estimation for Lithium-Ion battery Based on nonlinear observer: an $H_{\infty}$ Method. Journal of Energies 2017, vol. 10 issue 679, pp. 910-922; doi: 10.3390/en10050679.

[6] Juan Pablo Rivera-Barrera, Nicolás Muñoz-Galeano and Henry Omar Sarmiento-Maldonado, "SoC estimation for Lithium-ion batteries: review and future challenges". Journal of Electronics 2017, vol. 6 issue 102, pp. 910-922; doi: https://doi.org/10.3390/electronics6040102.

[7] Mingyu Gao, Yuanyuan Liu and Zhiwei He, "Battery State of Charge online estimation based on Particle Filter". 2011 4th International Congress on Image and Signal Processing, doi: 10.1109/CISP.2011.6100603.

[8] Xiaosong $\mathrm{Hu}$, Fengchun Sun and Yuan Zou, "Estimation of State of Charge of a Lithium-Ion Battery Pack for Electric Vehicles Using an Adaptive Luenberger Observer". Journal of Energies 2010, vol. 3, pp. 1586-1603; doi: 10.3390/en3091586.
[9] Yuejiu Zheng, Languang Lu, Xuebing Han, Jianqiu Li and Minggao Ouyang, "LiFePO4 battery pack capacity estimation for electric vehicles based on charging cell voltage curve transformation”. Journal of Power Sources 2013, vol. 226, pp. 33-41; doi: https://doi.org/10.1016/j.jpowsour.2012.10.057.

[10] Xiaosong Hu, Fengchun Sun and Yuan Zou, "State of Charge estimation of Li-ion battery in EVs based on second-order sliding mode observer". 2014 IEEE Conference and Expo Transportation Electrification AsiaPacific (ITEC Asia-Pacific); doi: 10.1109/ITEC-AP.2014.6941100.

[11] A. Affanni, A. Bellini, C. Concari, G. Franceschini, E. Lorenzani, and C. Tassoni, "EV Battery State of Charge: Neural network based estimation". IEEE International Electric Machines and Drives Conference, 2003. IEMDC'03; doi: 10.3390/en3091586.

[12] Xiaosong $\mathrm{Hu}$, Shengbo $\mathrm{Li}$ and Huei Peng, "A comparative study of equivalent circuit models for Li-ion batteries". Journal of Power Sources 2012, vol. 198, pp. 359-367, doi:10.1016/j.jpowsour.2011.10.013.

[13] Wei He, Michael Pecht, David Flynn and Fateme Dinmohammadi, "A Physics-Based Electrochemical Model for Lithium-Ion Battery State-ofCharge Estimation Solved by an Optimised Projection-Based Method and Moving-Window Filtering”. Journal of Energies 2018, vol. 11, doi: 10.3390/en11082120 .

[14] Long Chen, Ruyu Xu, Weining Rao, Huanhuan Li, Ya-Ping Wang, Tao Yang and Hao-Bin Jiang, "Electrochemical Model Parameter Identification of Lithium-Ion Battery with Temperature and Current Dependence”. International journal of electrochemical science 2019 , doi:10.20964/2019.05.05.

[15] Bizhong Xia, Wenhui Zheng Ruifeng Zhang, Zizhou Lao and Zhen Sun, "A Novel Observer for Lithium-Ion Battery State of Charge Estimation in Electric Vehicles Based on a Second-Order Equivalent Circuit Model". Journal of Energies 2017, vol. 10; doi:10.3390/en10081150.

[16] Qianqian Wang, , Jiao Wang, Pengju Zhao, , Jianqiang Kang, Few Yan and Changqing Du, "Correlation between the model accuracy and modelbased SOC estimation”. Journal Electrochimica Acta, vol. 228, pp. 146159; doi: https://doi.org/10.1016/j.electacta.2017.01.057.

[17] K. Saqli, H. Bouchareb, A.Naamane, N.K. M'Sirdi, and M. Oudghiri, "Battery Pack Thermal Modeling, Simulation and electric model Identification", "unpublished".

[18] Yuri Shtessel, Christopher Edwards, Leonid Fridman and Arie Levant, "Sliding mode control and observation". Springer Science+Business Media New York 2014; doi: 10.1007/978-0-8176-4893-0.

[19] Silvina I. Biagiola and José L. Figueroa, "A high gain nonlinear observer: application to the control of an unstable nonlinear process". Computers and Chemical Engineering 2004, vol. 28, pp. 1881-1898; doi: 10.1016/j.compchemeng.2004.03.004.

[20] Yong Tian, Chaoren Chen, Bizhong Xia, Wei Sun, Zhihui Xu and Weiwei Zheng. "An Adaptive Gain Nonlinear Observer for State of Charge Estimation of Lithium-Ion Batteries in Electric Vehicles". Energies 2014, 7, 5995-6012; doi:10.3390/en7095995.

[21] Hongfei Zhang, Zhumu Fu and Fazhan Tao. "Improved sliding mode observer-based SOC estimation for lithium battery”. AIP Conference Proceedings 2122 (2019); doi: https://doi.org/10.1063/1.5116497.

[22] Nacer K. M'Sirdi, Ahmed Belhani and Aziz Naamane. "Battery Models for Estimation of State of Charge by Sliding Mode Observer". Sustainability in Energy and Buildings, SIST 12, pp. 133-149. 